Document downloaded from:

http://hdl.handle.net/10251/91868

This paper must be cited as:

Segovia López, EF.; Salvador Moya, MD.; Sahuquillo Navarro, O.; Vicente Escuder, A. (2007). Effects of Long-term Exposure on E-glass Composite Material Subjected to Stress Corrosion in a Saline Medium. Journal of Composite Materials. 41(17):2119-2128. doi:10.1177/0021998307074134

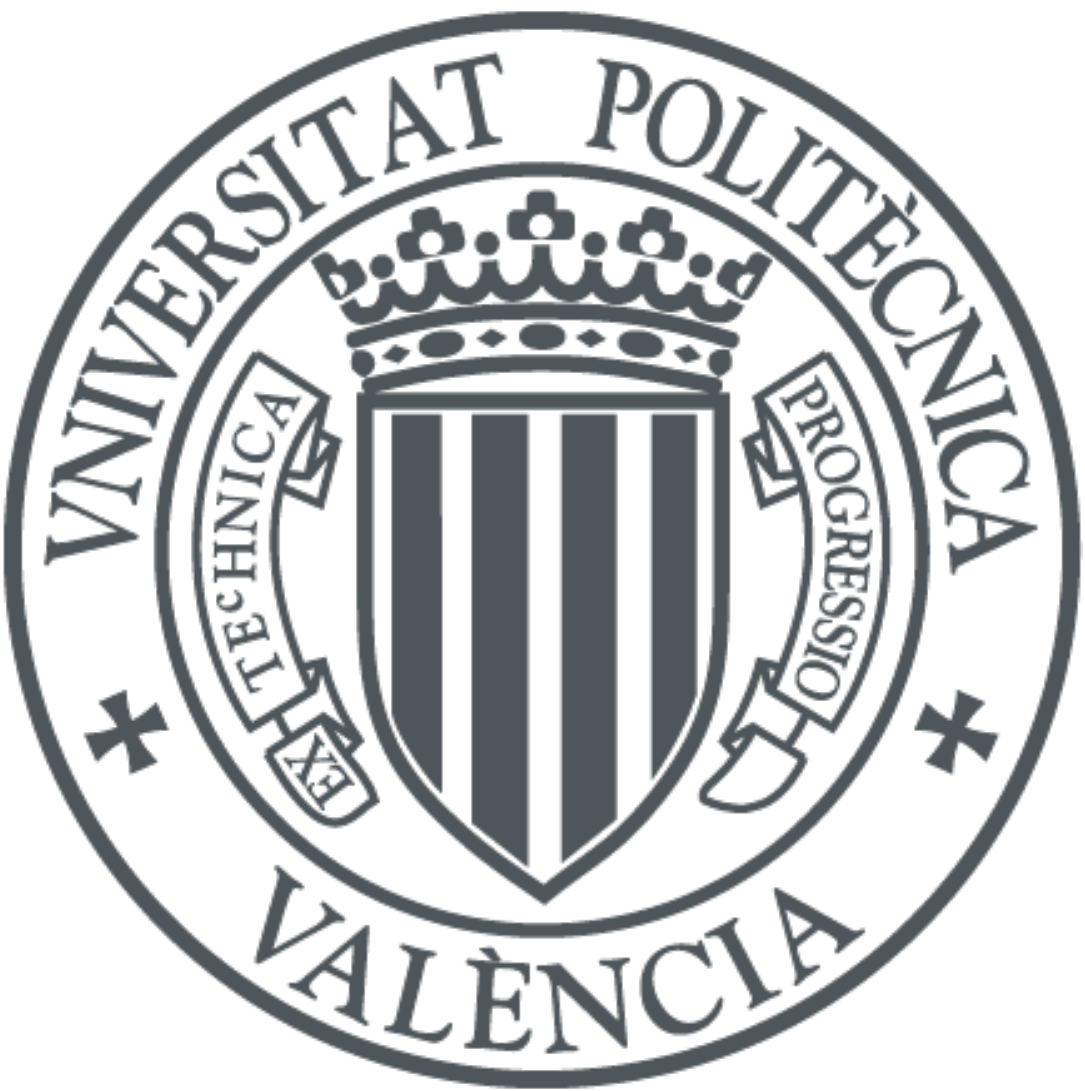

The final publication is available at

http://doi.org/10.1177/0021998307074134

Copyright SAGE Publications

Additional Information 


\title{
Effects of Long-Term Exposure on E-Glass Composite Material Subjected to Stress Corrosion in a Saline Medium.
}

\author{
F. SEGOVIA ${ }^{1, *}, M^{a}$.D. SALVADOR ${ }^{1}$, O. SAHUQUILLO ${ }^{1}$, A. VICENTE ${ }^{1}$, \\ ${ }^{1}$ Laboratory of Polymer and Composite Materials \\ Materials Technology Institute. Polytechnic University of Valencia \\ 46022 Valencia, Spain
}

\begin{abstract}
This work provides an insight on very long-term degradation of polyester-fibre glass composites immersed more than 30000 hours in saline medium under service stresses. Samples were loaded under bending conditions with stresses both in the elastic and plastic fields. With the result that characteristics in a flexural mode were able to be determined and the ensuing decrease in characteristics was fitted to an exponential model. The degree of losses ranged from 25 to $31 \%$ for the bending modulus, from 28 to $35 \%$ for the flexural strength, and from 40 to 51\% for the specific fracture energy. The most notable losses were for specimens immersed in artificial sea water under a continuous stress of $140 \mathrm{MPa}$, corresponding to the plastic behaviour of the material. Although the existence of matrix plasticization is doubtless, the osmotic effects of the diffusion on the matrix and the junction to the fibres, the presence of microcracks, and the effects of chemical ions in the medium on the surface fibre composition became evident in the strength degradation of the material.
\end{abstract}

KEY WORDS: E-glass, composite, long-term ageing, corrosion under stress, saline medium

*Author to whom correspondence should be addressed. E-mail: fsegovia@mcm.upv.es 


\section{INTRODUCTION}

Composite materials of a polymeric matrix reinforced with GFRP fibreglass permit the design of light pieces and equipment, resistant to loads. One of the most interesting qualities is that chemical resistance is achieved at an acceptable cost, and, in this respect, it proves superior to metals in many cases. The applications related to a marine environment: sports materials, ship hulls, and naval, military, industrial and commercial equipment are of increasing economic importance. In exposures to aqueous and saline mediums, various effects and types of damage are presented, such as matrix plasticization [1,2], surface blistering [1,3], attack on the fibre, the matrix or the fibrematrix interface [2-10], and internal tensions which increase the fragility of the material $[1,6,11-15]$, as a consequence of the diffusion of water and the components dissolved within it.

There are few cases in which the modification of the mechanical characteristics is due to exposure to saline mediums and other types of service conditions under load $[3,4,16,17]$. Papers dedicated to study exposure periods of over 10000 hours are very scarce $[10,18]$. The objective of this study is to determine the effect of the prolonged exposure of GFRP materials made from polyester and glass fibre to a saline medium under bending load conditions, with regards to degradation under stress.

\section{EXPERIMENTAL STAGE}

\section{Materials}

The composite material was elaborated through contact moulding, and subsequent curing at $40{ }^{\circ} \mathrm{C}$ over 24 hours. It consisted of 8 layers of 1:1 taffeta tissue in E-glass by Vetrotex, with a density of $300 \mathrm{~g} / \mathrm{m}^{2}$ and symmetric orthonormal orientation (0-90) $8 \mathrm{~s}$. The percentage of the volume of porosity $3.5 \pm 1.5$, the percentage of the volume of 
fibre was $33 \pm 2$, and the density $1.61 \pm 0.02 \mathrm{~g} / \mathrm{cm}^{3}$. The resin used was Palatal ${ }^{\mathrm{TM}} \mathrm{U} 541$ TV by Basf, consisting of unsaturated ecologic polyester, of low styrene emission, on the basis of standard glycol and orthophthalic acid with a mean degree of cross-linking, with $41 \%$ of styrene content, and content below $1 \%$ on retardant waxes from styrene emission.

\section{Equipment and Test}

The test specimens were cut according to the ASTM 790M-86, with a length of $145 \pm 1$ $\mathrm{mm}$, a width of $24.5 \pm 0.2 \mathrm{~mm}$ and with $3.2 \pm 0.1 \mathrm{~mm}$ of thickness. The length between supports was fixed at $113.0 \pm 0.1 \mathrm{~mm}$ and the testing velocity at $5.0 \pm 0.1 \mathrm{~mm} / \mathrm{min}$. The elastic modulus $\mathrm{E}$, the ultimate strength $\mathrm{R}$ and the BSE specific fracture energy, corresponding to the area under the curve tension-deformation up to the maximum load, were determined. Between 5 and 8 samples per condition were tested using an Instron 4202 universal testing machine.

A saline medium, imitating sea water, with a salt concentration of $5 \%$ was selected. The following immersion times were taken: 0, 1000, 5000, 10000, 15000, 20000, 30000 and 36000 hours. The load levels present during immersion were fixed at 0, 90, $140 \mathrm{MPa}$, which, respectively represent $0,28 \%$ and $44 \%$ of the maximum resistance or ultimate flexural stress. For this, an instrument made of AISI 304L stainless steel such as that shown in Figure 1 was used. Two test coupons were placed inside this instrument and subsequently, forced to take the deflection corresponding to a load of 90 and $140 \mathrm{MPa}$. Prior to this, the values obtained from the registers of tension-deflection for the reference sample corresponding to 0 hours of immersion, were loaded. Thus, 0, 90 and $140 \mathrm{MPa}$ correspond to deflections of 0, 4 and $6 \mathrm{~mm}$. 
The $\mathrm{pH}$ of the medium was measured during the exposure time. In addition, the chemical composition of the E-fibreglass taffeta tissue was determined by the microanalysis of dispersive energies using a Jeol JSM 6300 scanning electron microscope.

\section{RESULTS}

\section{Elastic Modulus}

The evolution of the E elastic modulus with regards to the immersion time is presented in Figure 2. In line with the findings of other authors, an exponential reduction can be observed for several mechanical properties [1,10,19-22]. The composite, not subjected to tension during its exposure, $0 \mathrm{MPa}$, registers losses of around $25 \%$ following those 36000 hours. Thus, modulus lowered from 17.7 GPa to $13.3 \mathrm{GPa}$. Specimens exposed to a $90 \mathrm{MPa}$ tension, which is within the limit of the zone corresponding to the elastic period, show slightly superior losses, 27\%, equivalent to $12.9 \mathrm{GPa}$. For a working stress of $140 \mathrm{MPa}$, a tension clearly located within the plastic behaviour of the material, the loss is greater, $31 \%$. In this case, the elastic modulus reaches $12.3 \mathrm{GPa}$.

\section{Flexural strength}

Once again, in Figure 3 it can be observed how the flexural strength $\mathrm{R}$ of the composite diminishes exponentially with the immersion time. The group of samples which do not support any working load, exposed to the saline medium registers a $28 \%$ reduction in its strength following an immersion period of 36000 hours. That means the strength is reduced from 319 to $230 \mathrm{MPa}$. In coupons submerged under stress of $90 \mathrm{MPa}$ this property varies up to $222 \mathrm{MPa}$ and also registers slightly greater losses, 30\%. For the 
same period of exposure to the saline medium under a continuous load of $140 \mathrm{MPa}$, the strength is $208 \mathrm{MPa}$ and losses reached 35\%.

\section{Fracture energy}

The break specific energy BSE quantifies the toughness of the material [21-24], since it represents the energy balance during the deflection and the loading of the material up to its structural collapse or fracture. Figure 4 shows the results of immersion in a saline medium and the effect under loading. The initial toughness is quantified in $4.4 \mathrm{Jcm}^{-3}$. After a period of 36000 hours, the material exposed without load exhibits losses of $40 \%$, reaching the value of $2.7 \mathrm{Jcm}^{-3}$. Almost the same result, $42 \%$ is recorded in reference to the losses in the toughness, $2.6 \mathrm{Jcm}^{-3}$, for the specimens exposed under a 90 MPa of load. These extend to $51 \%$ when the test coupons are submerged and put into use under a load of $140 \mathrm{MPa}$. Their BSE reaches $2.2 \mathrm{Jcm}^{-3}$. The value of the losses found for this characteristic significantly surpasses the value of those occurring for the characteristics of modulus and flexural strength, regardless of the load to which they have been submitted during immersion. It is also observable that the three mechanical characteristics continue to diminish beyond the 20000 hours of immersion in the case of the samples under a $140 \mathrm{MPa}$ load, an aspect which is decelerated in the other two sample groups.

\section{DISCUSSION OF RESULTS}

The deterioration of the mechanical properties is justified in the first place, by the resin plasticization caused by the diffusion of water through the polymer and a certain degree of hydrolysis affecting the ester group [1-3,5,10]. Figure 5 shows that $\mathrm{pH}$ varied from 6.0 to 4.9 during the first 12000 hours. Consequently, it is very likely that there is 
massive hydrolysis of the resin occurring in the faces in contact with saline medium and beneath these ones. In fact, the weight of the composite augments due to water absorption. In Figure 6, it can be seen that the material without load reaches water uptake content close to the saturation point, $0.50 \%$, from 10000 hours onwards. However, the mechanical properties continue to decrease for greater periods of time. The same outcome occurs for specimens immersed under a load of $90 \mathrm{MPa}$, in which they practically reach the saturation value, 0.62\%, between 10000 and 20000 hours.

With an increase in the working stress up to $140 \mathrm{MPa}$, the diffusion capacity of the water up to $0.93 \%$ after 36000 hours does not appear to reach the level of equilibrium saturation during such a long exposure period. Meanwhile, it can also be observed that simultaneously the strength properties $\mathrm{R}$ and $\mathrm{E}$, and the toughness property BSE, diminish in a continuous mode. This indicates that there must be another cause of greater significance than that of the plasticization or partial hydrolysis of the matrix. Several authors have suggested the need to localise the attack on the fibre matrix interface [5-7].

For a load at the limit of the elastic behaviour, such as $90 \mathrm{MPa}$, deformations and internal tensions occur in the resin which can induce the appearance of microcracks, mainly in the interface or near the bonding between fibre and matrix [24]. This facilitates water penetration, the increase of the osmotic pressure exerted by water inside the microcracks and the porosity which is a characteristic of the material near the fibres. In addition, it also permits an increase in the level of internal tensions, producing weakening and decohesion between the fibre and the matrix. Thus, a discrete increase in the content amount of water absorbed and a slight reduction in mechanical properties in the samples under a load of $90 \mathrm{MPa}$, with regard to specimens submerged without a working load, can be observed. 
When the service load level is increased to $140 \mathrm{MPa}$, a value within the rank of the plastic behaviour of the material, the existence of an unquestionable superficial cracking can be observed, as illustrated in Figure 7. As a result of the capillary effect, a greater amount of water can penetrate and be distributed through these cracks until it reaches the zones of interfacial micro-cracking, thereby intensifying the attack on the interface at this point $[5-7,10]$. The result is an escalation in the losses of the strength properties $E$ and R. The increase in the density of cracks in areas where fibres oriented to $90^{\circ}$ are present causes the alteration of the fibre-matrix interface after long exposure periods $[7,24]$. The loss suffered in the BSE fracture energy provides indirect evidence of the deterioration of the interface between the fibre and the matrix [21-24]. This is of a greater extent to the losses which occurred in the resistance and the modulus, and agree with that observed by the researchers [25].

Several authors have proven that following the attack on the fibre-matrix interface, an attack on the fibre in the form of a $\mathrm{Na}^{+}, \mathrm{K}^{+}, \mathrm{Mg}^{2+}, \mathrm{Ca}^{2+}, \mathrm{B}^{3+}, \mathrm{Al}^{3+}$ cation lixiviation through the effect of the $\mathrm{H}^{+}$of the medium $[7,26,27]$, or due to the attack on the link SiO-Si [28], contributes to the appearance of the mechanism of corrosion under tension $[7,9,19,26-28]$, and is concentrated in the internal traction tensions at the fibre surface. This phenomenon sometimes appears and is intensified when the hydrolysis process of the ester group and the occurrence of osmotic delamination on the fibre interface are very advanced [8]. These chemical attacks on the fibre have been proven to be more energetic under temperatures above $60^{\circ} \mathrm{C}$ or in media where the $\mathrm{pH}$ becomes more extreme, both for acid media and with regard to alkali. In connection with our study, the saline medium, including hydrolysis products from resin, shows a weak acidic pH between 6.2 and 4.9, see Figure 5. The existence of unquestionable damage to the surface of the fibre, following long exposure periods, is highly probable as shown in 
Figure 8. The fractography of figure 9 shows the effects of the attack to the fibre surface. Because of the weakness of the attacked fibre, its surface presents a smooth aspect, cleaved resin, and massive pull-out. Even in the absence of external working stress, the reductions in the mechanical properties are greater than those presented by Liao [7]. The variations with an upward $(+)$ or downward $(-)$ trend for different immersion times for the content of the elements constituting the fibre are presented in Table I. The majority elements, $\mathrm{Si}$, $\mathrm{Ca}$ and $\mathrm{Al}$ and the minority elements $\mathrm{Mg}, \mathrm{Na}, \mathrm{K}, \mathrm{Fe}$, register changes, which demonstrate the credibility of the hypothesis regarding the attack on the fibre by the saline medium lightly acidic.

\section{CONCLUSIONS}

Prolonged exposure to saline media which imitates sea water produces significant deteriorations in the mechanical properties of the composite materials of polyester and fibreglass. These losses increase in the elastic modulus order by $25 \%$, in flexural strength by $28 \%$ and with regard to specific fracture energy by $40 \%$.

The exposure to this medium together with continuous working stress contributes to the increase in the losses within the different mechanical properties with regards to flexure. The difference with no-loaded samples is minimal in the case of flexural characteristics corresponding to the elastic period, $90 \mathrm{MPa}$, and greater in the case of a stress in the plastic period, $140 \mathrm{MPa}$. With regard to these working stresses, the losses in the modulus are $27 \%$ and $31 \%$, the losses in strength are $30 \%$ and $35 \%$, and $42 \%$ and $51 \%$ in fracture energy.

Whereas the diffusion of water reaches values near saturation point relatively quickly in prolonged exposures and with a low level of working load, the penetration of the marine 
medium on the material is continuous when high working tensions operate and does not reach saturation even after such an extended period as 36000 hours.

All this indicates that the reduction in the properties is mainly due to the degradation of the matrix-fibre bonding. This is helped by the existence of internal tensions in this area, by the osmotic effect which produces the presence of water which is mainly distributed by hydrolytic attack on the matrix-fibre bonding, primarily on the fibre. This process is stimulated by the presence of microcracks in the matrix. The degradation mechanism such as hydrolysis of the acid groups in the polyester and chemical attack to the fibre occur and it is also very important.

\section{ACKNOWLEDGEMENTS}

We would like to thank the $\mathrm{R}+\mathrm{D}+\mathrm{i}$ Linguistic Assistance Office at the Polytechnic University of Valencia for their help in revising this paper.

\section{REFERENCES}

1. Castaing, Ph., Lemoine, L. and Tsouvalis, N. (1993). Experimental study of the variation in mechanical characteristics of orthotropic laminates immersed in water. In: Proceedings of the $9^{\text {th }}$ International Conference on Composite Materials. July 12-16, pp. 577-584.

2. Weitsman, Y.J. (1998). Progress in Durability Analysis of Composite Systems. NL: A.A. Balkema Ed.

3. Karama, M., Touratier, M. and Pegorarol, P. (1993). Test of accelerated aging composites material in shipbuilding. In: Proceedings of the $9^{\text {th }}$ International Conference on Composite Materials. July 12-16, pp. 585-592. 
4. Adams, R.D. and Singh, M.M. (1996). Progress in Durability Analysis of Composite Systems. NL: A.A. Balkema Ed.

5. Siddaramaiah, Suresh, S.V., Atul, V.B., Srinivas, D. and Girish, S. (1999). Effects of aggressive environmental on composite materials. Journal of Applied Polymers, 73(5): 795-799.

6. Boinard, E., Pethrick, R.A., Dalzel-Job, J. and McFarlane, C.J. (2000). Influence of resin chemistry on water uptake and environmental ageing in glass fibre reinforced composites-polyester and vinyl ester laminates. Journal of Materials Science, 35(8): 1931-1937.

7. Liao, K., Shultheisz, C.R. and Hunston, D.L. (1999). Effects of environmental aging on the properties of pultruded GFRP. Composites B, 30(5): 485-493.

8. Chin, J.W., Aouidi, K., Haight, M.R., Hughes, W.L. and Nguyen T. (2001). Effects of water, salt solution and simulated concrete pores solution on the properties of composite matrix resins used in civil engineering applications. Polymer Composites, 22(2): 282-297.

9. Kajorncheappunngam, S., Gupta, R.K. and Rao, H.V.S. (2002). Effect of aging environment on degradation of glass-reinforced epoxy. Journal of Composite in Construction, 6(1): 61-69.

10. Chu, W., Wu, L. and Karbhari, V.M. (2004). Durability of moderate temperature cured E-glass/vinylester systems. Composite Structures, 66: 367-376.

11. Peppas, N.A. and Lee, M.C. (1993). Models of moisture transport and moistureinduced stresses in epoxy composites. Journal of Composite Materials, 27(12): 1146-1171. 
12. Boukhili, R., Bojji, C. and Gauvin R. (1994). Fatigue mechanisms under low energy repeated impact of composite laminates. Journal of Reinforced Plastic Composites, 13(10): 856-870.

13. Selzer R. and Friedrich K. (1993). Effects of water up-take on interlaminar fracture properties of various carbon fiber/epoxy composites. In: Proceedings of the $9^{\text {th }}$ International Conference on Composite Materials. July 12-16, pp. 875-881.

14. Springer, G.S., Sanders, B.A. and Tung, R.W. (1980). Environmental effects on glass fiber reinforced polyester and vinylester composites. Journal of Composite Materials, 14: 213-233.

15. Smith, C.S. (1990). Design of marine structures in composite materials. ENG: Elsevier Ed.

16. Choqueuse, D., Davis, P. and Mazéas, F. (1998). Progress in Durability Analysis of Composite Systems. NL: A.A. Balkema Ed.

17. Serrano M.A. and Güemes A. (1995). Análisis de efectos ambientales sobre uniones mecánicas en laminados vidrio-viniéster. In: Proceedings of the $3^{\text {rd }}$ Congreso Nacional de Materiales Compuestos. November 29-30, pp. 289-294.

18. Kemmochi, K., Xia, M., Takayannagi, H. and Fukuda, H. (2002). Durability Analysis of Composite Systems. NL: Ed. Swets \& Zeitlinger B.V.

19. Sonawala, S.P. and Spontak, R.J. (1996). Degradation kinetics of glass-reinforced polyesters in chemical environments 2: Organic solvents. Journal of Materials Science, 31: 4757-4765.

20. Davis, P. and Roy, A. (2000). Recent Developments in Durability Analysis of Composite Systems. NL: A.A. Balkema Ed. 
21. Segovia, F., Ferrer, C., Salvador, M.D. and Amigó, V. (2001) Influence of processing variables on mechanical characteristics of sunlight aged polyester glass fibre composites. Polymer Degradation and Stability, 71(1): 179-184.

22. Segovia, F., Ferrer, C., Salvador, M.D. and Amigó, V. (2002). Flexural characteristics of sun-aged polyester composites: influence of processing variables. Journal of Testing and Evaluation, 30(1): 20-26.

23. Segovia, F., Ferrer, C., Salvador, $M^{\mathrm{a}}$ D., Vicente, A. and Amigó, V. (2001). Evolución del comportamiento a tracción de composites poliéster y fibra de vidrio sometidos a degradación térmica y lumínica. Revista de Metalurgia, 37(7): 250-254.

24. Segovia, F., Salvador, M.D., Amigó, V. and Vicente, A. (2003). Cure treatment influence on post-impact tensile characteristics of 2D epoxy composites. Journal of Materials Processing Technology, 143-144: 209-213.

25. Verghese, K.N., Hayes, M.D., García, K., Carrier, C., Word, J., Riffle, J.R. and Lesko, J.J. (1999). Influence of matrix chemistry on the short term, hydrothermal aging of vinyl ester matrix and composites under both isothermal and thermal spiking conditions. Journal of Composite Materials, 33: 1918-1938.

26. Metcalfe, A.G. and Schmitz, G.K. (1972). Mechanism of stress-corrosion in E-glass filaments”. Glass Technology, 13(1): 5-16.

27. Qiu, Q. and Kumosa, M. (1997). Corrosion of E-glass fibres in acidic environments. Composite Science Technology, 57(5): 497-507.

28. Michalske, T.A. and Freiman, S.W. (1983). A molecular mechanism for stresscorrosion in vitreous silica. Journal of American Ceramic Society, 66(4), 284-288. 
Table I. Variation in \% of the element contents in the fibre.

\begin{tabular}{cccccccc}
\hline $\mathrm{t}($ hours $)$ & $\mathrm{Na}$ & $\mathrm{Mg}$ & $\mathrm{Al}$ & $\mathrm{Si}$ & $\mathrm{K}$ & $\mathrm{Ca}$ & $\mathrm{Fe}$ \\
\hline 48 & -86 & +8 & -9 & +3 & -6 & -6 & +1060 \\
120 & +329 & +6 & -6 & -1 & +6 & -9 & +540 \\
240 & +300 & +8 & -7 & -4 & -41 & -15 & +470 \\
456 & -100 & +3 & -7 & -1 & -29 & -9 & +700 \\
745 & +229 & +8 & -7 & -2 & -53 & -4 & +380 \\
1825 & -100 & +7 & -11 & -7 & -65 & -13 & +380 \\
3000 & +186 & +13 & -3 & +8 & +65 & -1 & +340 \\
\hline
\end{tabular}




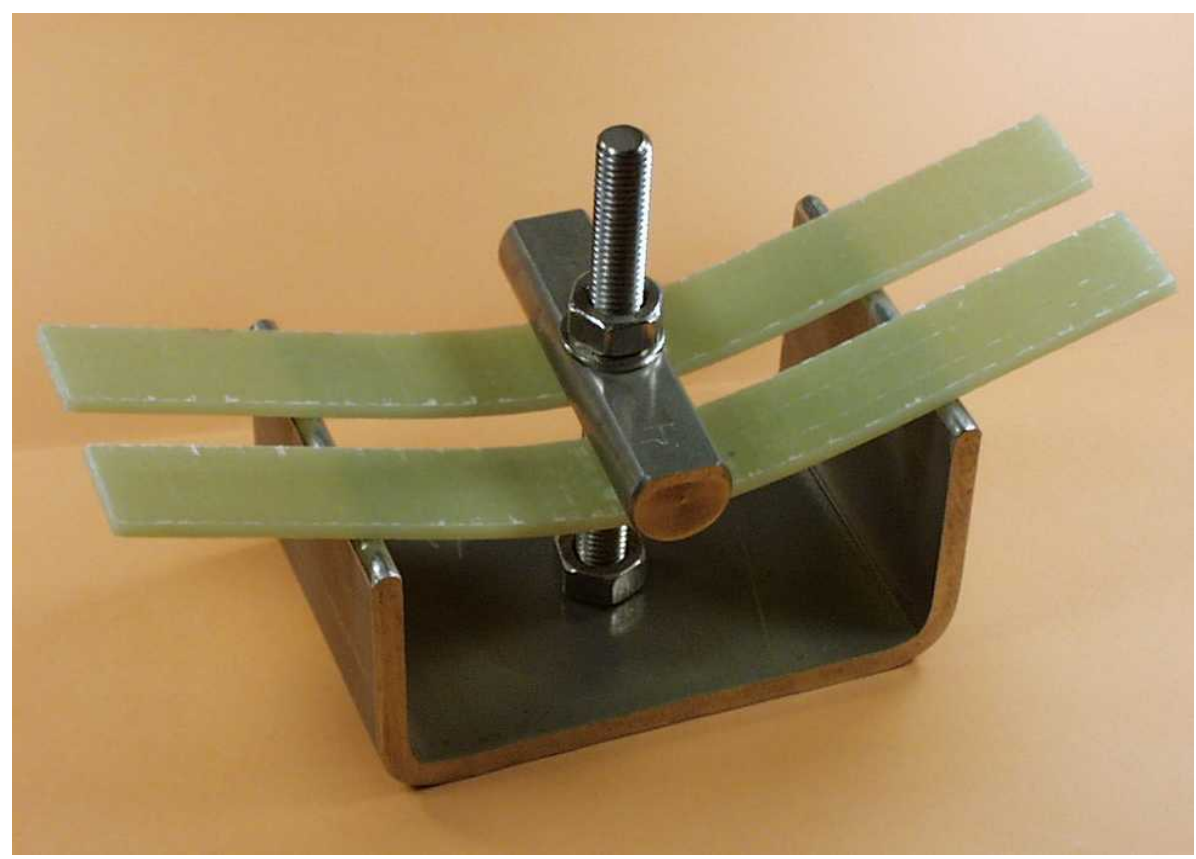

Figure 1. Device to apply the service stress to samples submerged in sea water medium. 


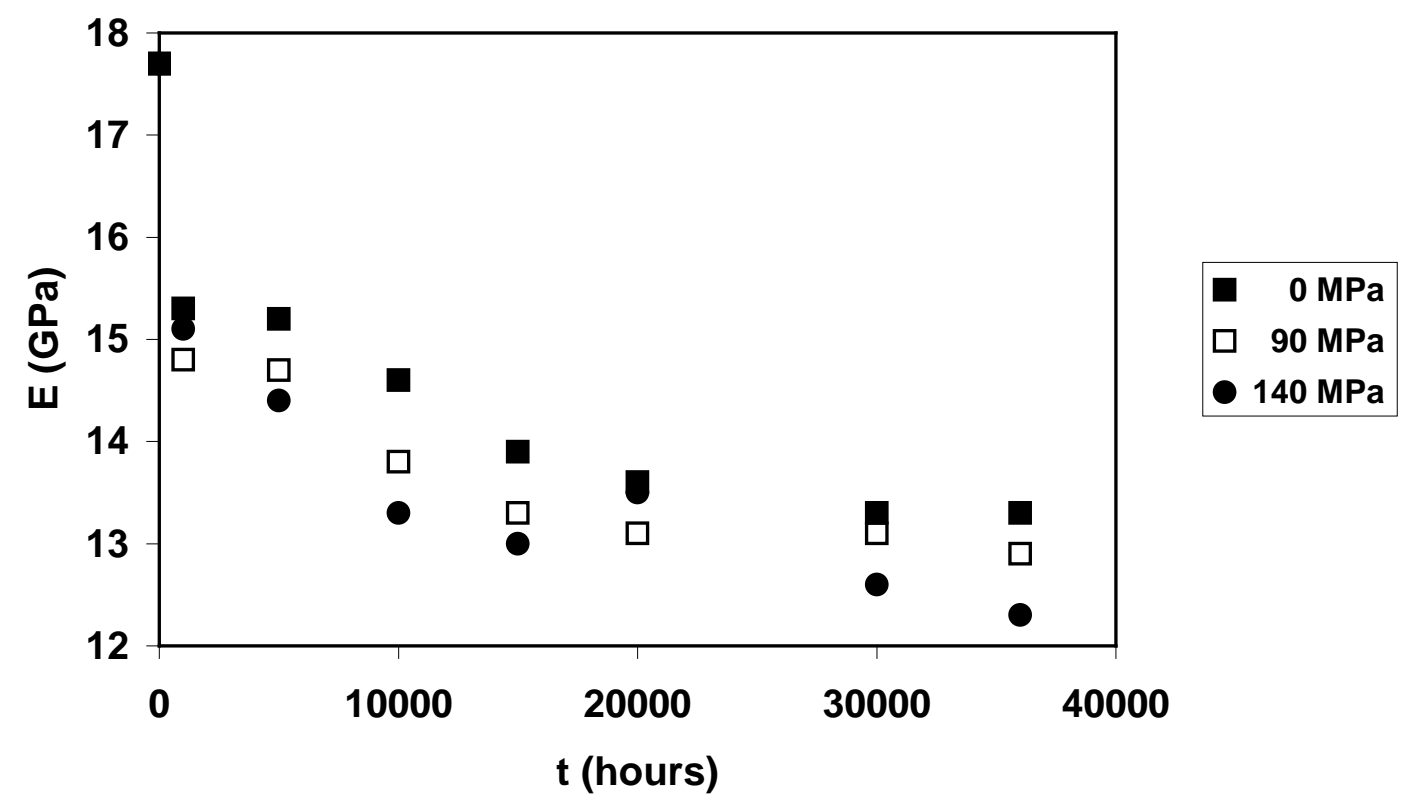

Figure 2. Bending modulus in relation to the immersion time and service stresses.

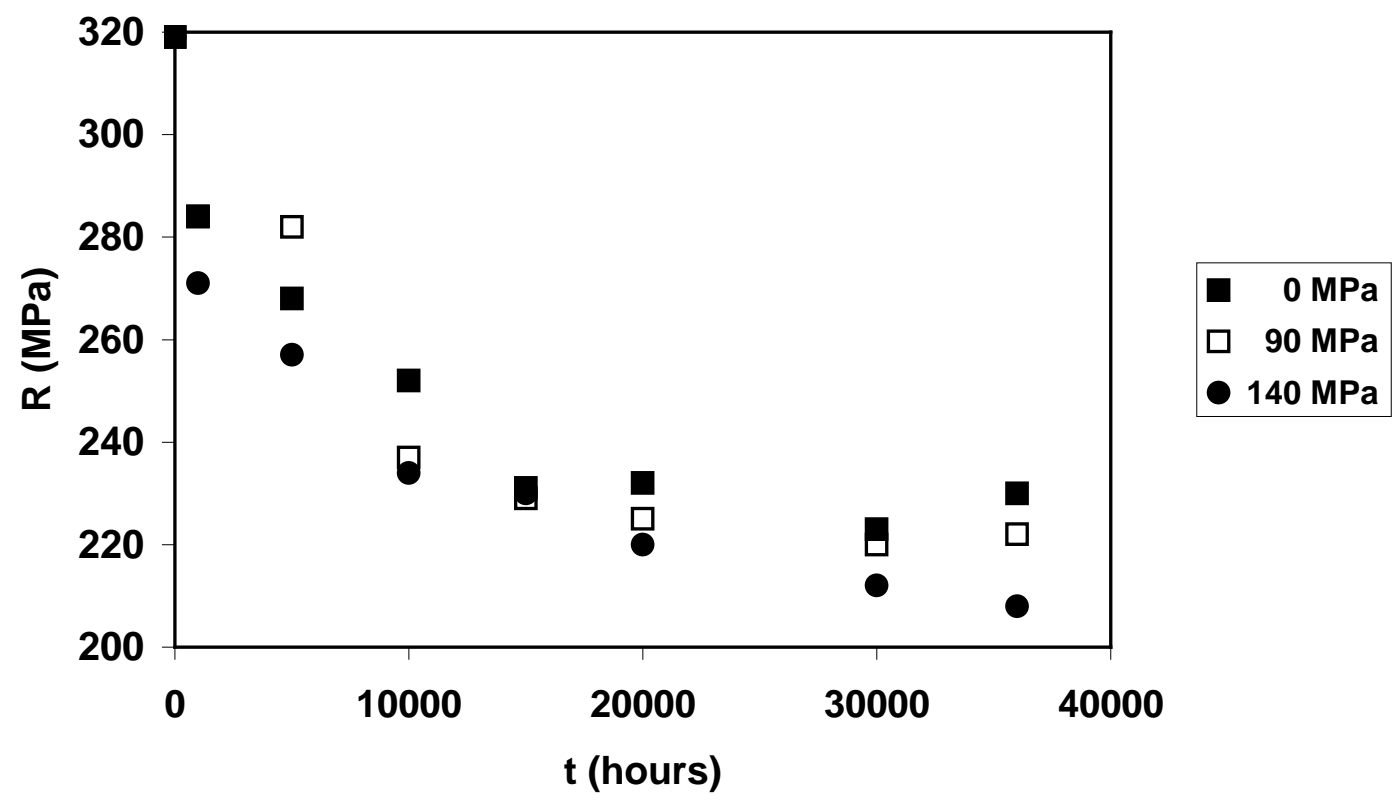

Figure 3. Flexural strength in relation to the immersion time and service stresses. 


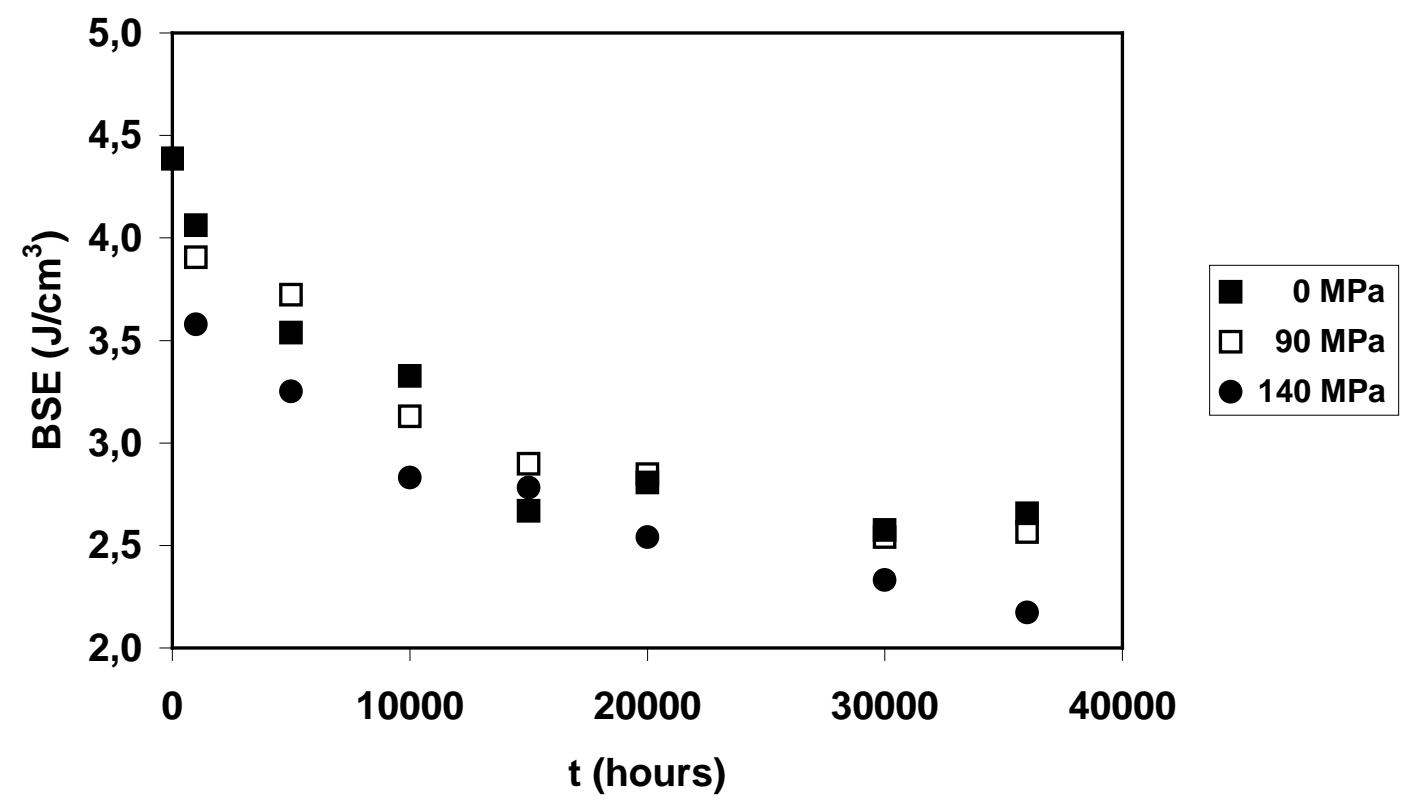

Figure 4. Specific fracture energy in relation to the immersion time and service stresses.

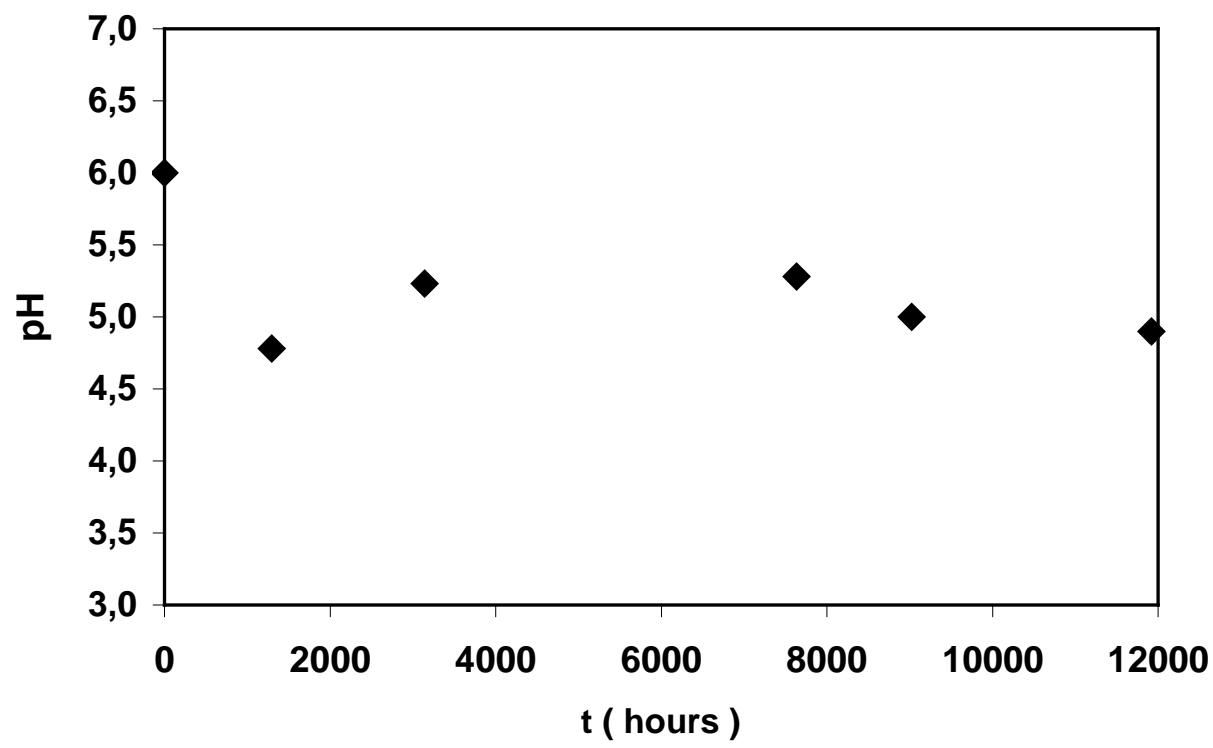

Figure 5. Evolution of the $\mathrm{pH}$ of the saline solution with the exposure time 


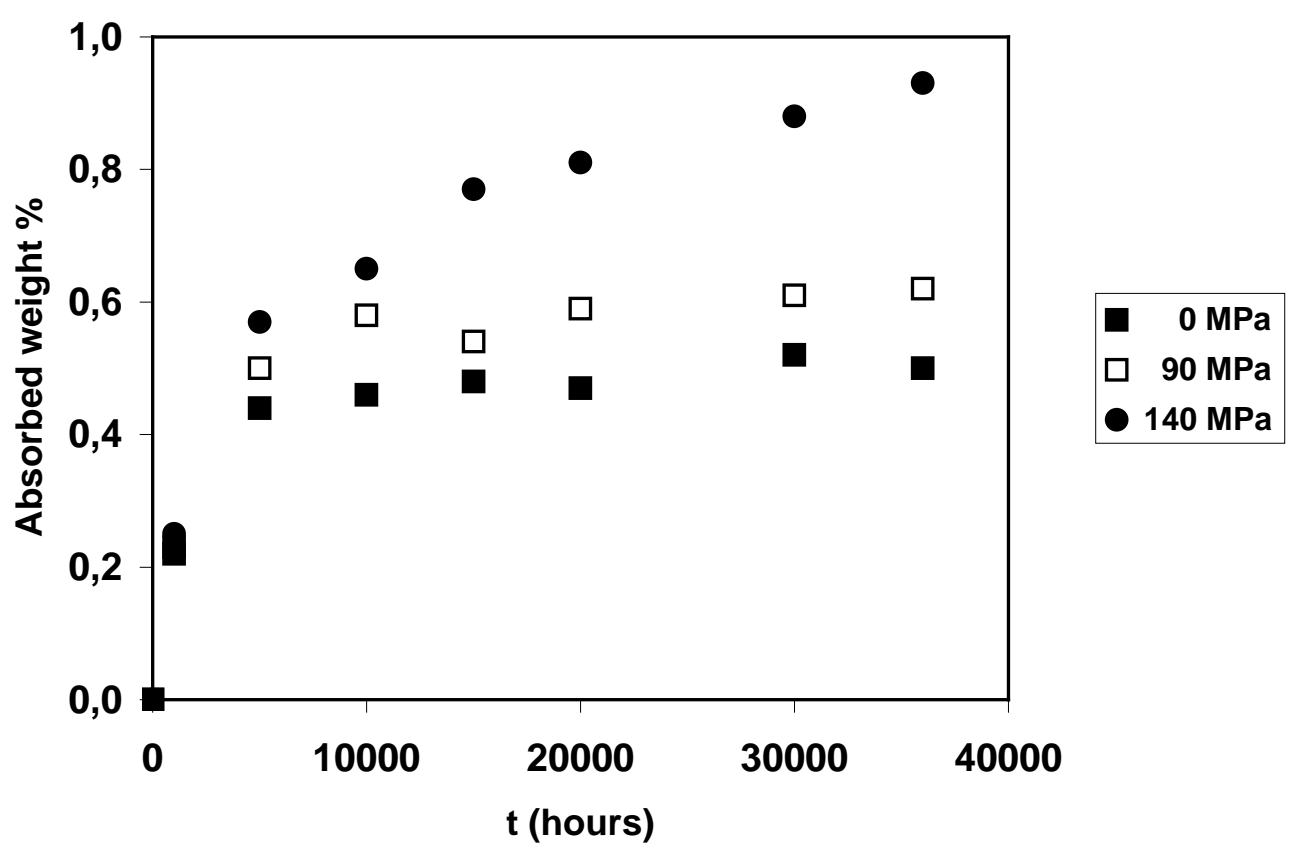

Figure 6. Water absorption in relation to the exposure time

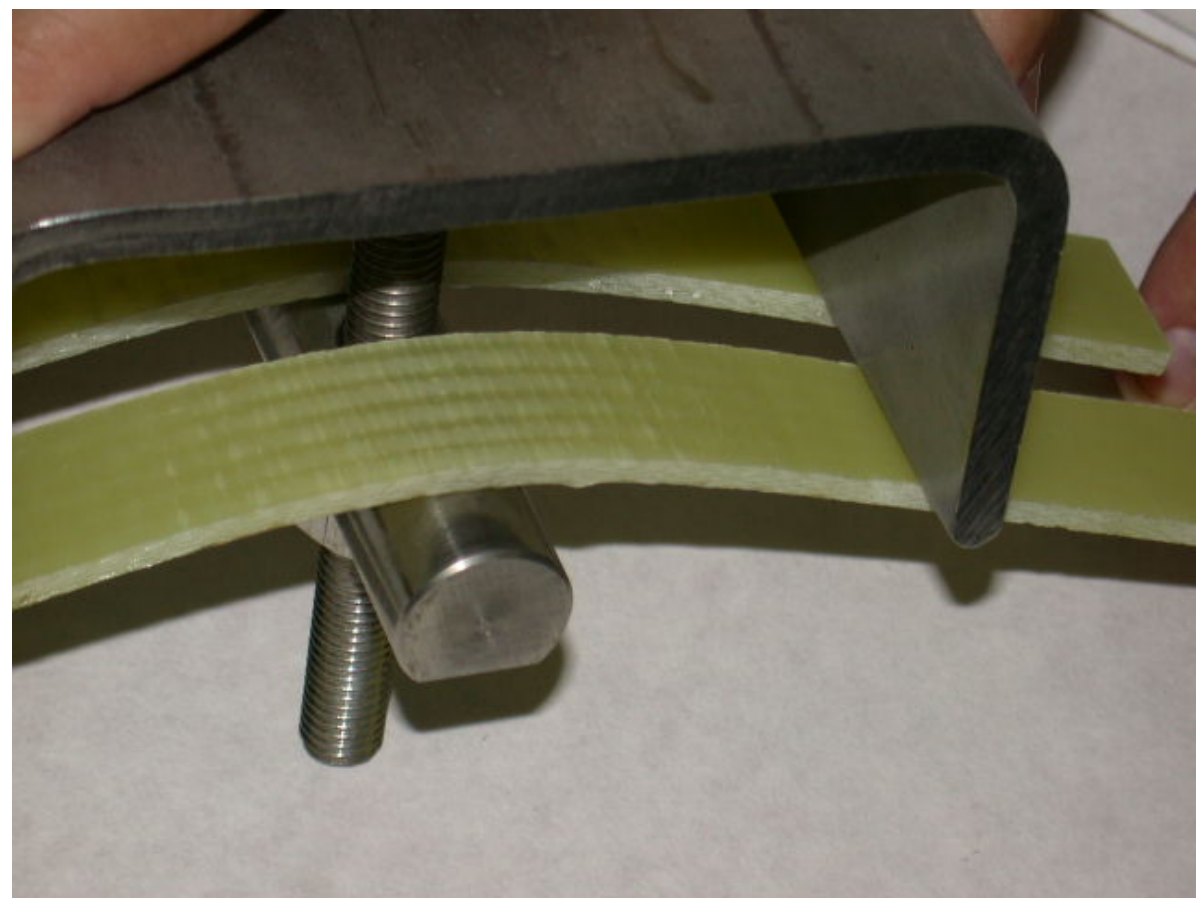

Figure 7. Cracks in coupon for a working stress of $140 \mathrm{MPa}$ after 10000 hours. 


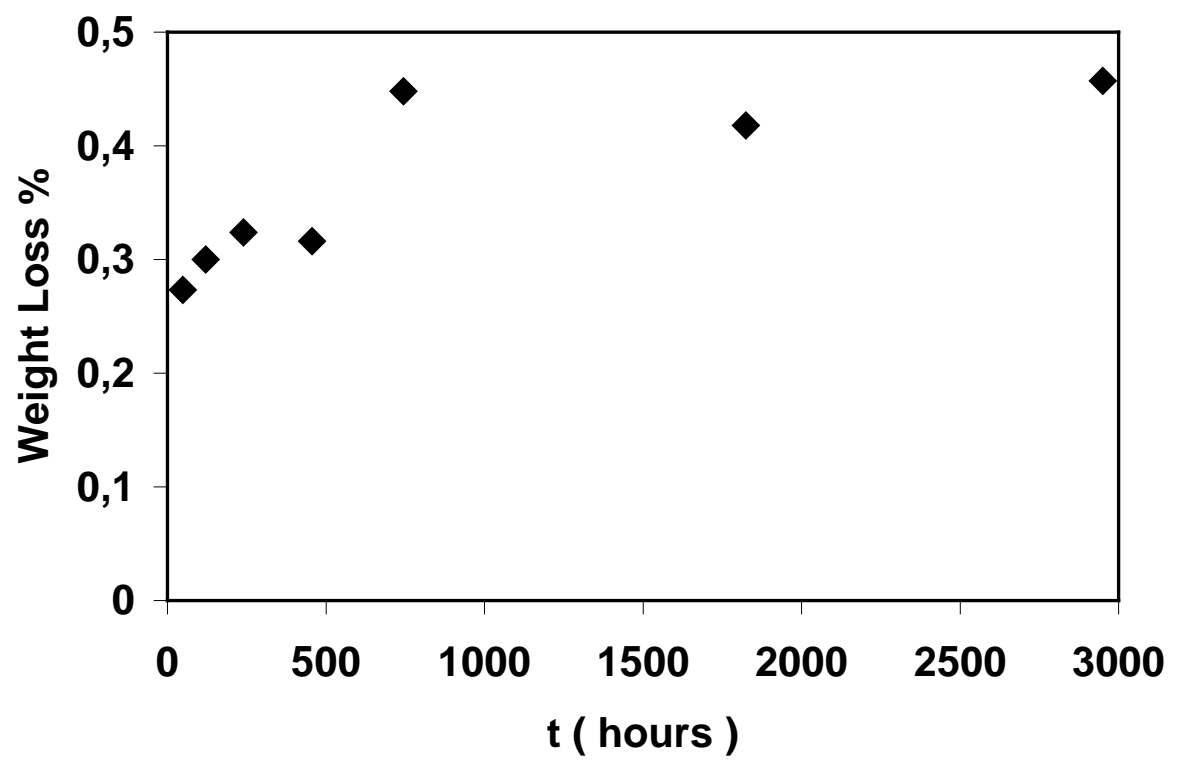

Figure 8. Weight loss in the fibre glass with the exposure time.

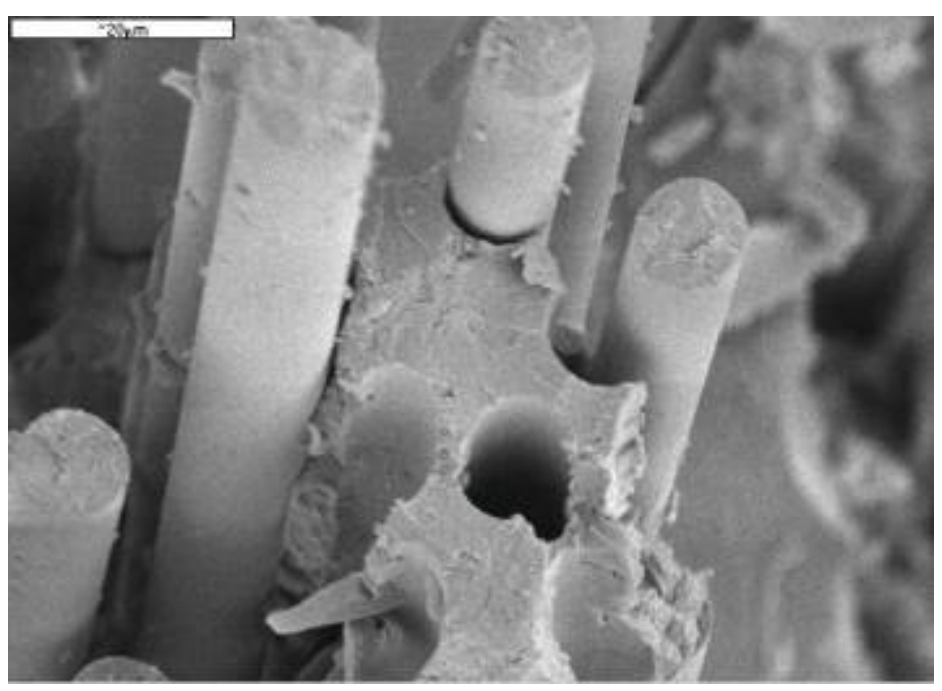

Figure 9. Debonding and pull-out of glass fibreglass at 13000 hours. X1500. 